\title{
La ciudad y lo efímero. La ciudad escuchada
}

\author{
Javier BONED PURKISS \\ Unidad Administrativa de Arquitectura \\ Escuela de Arquitectura de Málaga. Universidad de Málaga \\ fjboned@uma.es
}

Recibido: 30 de septiembre de 2011

Aceptado: 4 de octubre de 2011

\begin{abstract}
Resumen
¿Cómo se podría actuar en la ciudad en esta época sin recursos? La época "sin recursos" debería propiciar cuestiones de tipo ético, desde una estética implícita donde la belleza ya no será tanto un juicio de valor como una facultad de crear sentido, auspiciar nuevas vivencias de la ciudad desde la aceptación del tiempo y de su alteridad como principal atributo. El arquitecto está obligado a cambiar el enfoque, mirando el mundo con otra lógica.

La ciudad entendida como "ser musical", implicaría expandir o ampliar la percepción que de ella tenemos, volver sensibles, sonoras, las fuerzas ordinariamente imperceptibles. El reto pasaría por hacer del sonido el intermediario que vuelva el tiempo sensible, organizar el material, la ciudad, para captar las fuerzas del tiempo y volverlo sonoro.
\end{abstract}

Palabras clave: efímero, sin recursos, escucha, paisaje sonoro.

Title: The City and the ephemeral. The city listened

Abstract

How would you act in the city at this time without resources? The time "without resources" should lead to ethical issues, from an implicit aesthetic where beauty and not value judgments but a power to create meaning, sponsoring new experiences of the city from the acceptance time and alterity as its main attribute. The architect is obliged to change the focus, looking at the world with a different logic.

The city understood as being "musical", would expand and extend the perception of it have, become sensitive, sound, usually imperceptible forces. The challenge would be based on that the sound was the intermediary that is capable of turning the sensitive time, organize material, the city, to capture the forces of time and make it sound.

Keywords: ephemeral, no-resources, listening, soundscape.

\section{Índice}

1. La ciudad y lo efímero

2. La ciudad escuchada

\section{La ciudad y lo efímero}

Ante el hecho incuestionable de una época sin recursos, la arquitectura y la ciudad deberán preguntarse sobre su 
funcionamiento y cómo encarar el carácter de sus intervenciones. No parece fácil afrontar un periodo de carencias desde posiciones estéticas y espaciales respaldadas por elevados presupuestos, estando en la obligación los arquitectos de afrontar el problema y suscitar reflexiones y debates que propicien futuras y posibles metodologías de intervención. ¿Cómo se podría, sin ir más lejos, actuar en la ciudad en esta época sin recursos? ¿Cómo operar en su complejidad en esta sociedad de los flujos y de la inestabilidad globalizada? ¿Qué nuevos retos cabría plantearse frente a la vieja cultura de los objetos y su permanencia?

Podríamos empezar por acercarnos al concepto de lo efímero, ideas y propuestas de intervención que tiendan a revitalizar los espacios urbanos mediante proyectos que permitieran transformaciones con medios y recursos mínimos. Proyectos ingeniosos, que permitieran revisar la noción del espacio urbano utilizable desde experiencias artísticas contemporáneas y propiciar el debate y la reflexión sobre el hecho arquitectónico actual y su relación con la sociedad. Sin duda, la principal cualidad de esta reflexión se basa en el carácter "efímero" de estas intervenciones. Efímero entendido como:

[...] modalidad del tiempo en nuestra era de la globalización, lo que conlleva una aceleración y desenraizamiento de las estabilidades. [...] Se asiste así al final de las grandes narraciones y se abre paso una lógica de la instantaneidad. (Buci-Glucksmann 2006: 15)

La época sin recursos debería propiciar, gracias a esto, cuestiones de tipo ético, desde una estética implícita donde la belleza ya no será tanto un juicio de valor como una facultad de crear sentido, auspiciar nuevas vivencias de la ciudad desde la aceptación del tiempo y de su alteridad como principal atributo. Serán operaciones de levedad, de ligereza, sabiendo que la pesadez, la inercia, la opacidad, se adherirán de nuevo rápidamente a la arquitectura si no se encuentra la manera de evitarlas, y una época sin recursos está en el deber de hacerlo. El arquitecto está así obligado a imaginar otros lugares, cambiando el enfoque, mirando el mundo con otra lógica. Se impondrían las actuaciones con tecnologías blandas, materiales básicos y herramientas mínimas, superando el concepto de diseño minucioso, planeado, sin cerrarlo bajo ninguna de las formas de la armonía tradicional, sino sometiéndolo a todo tipo de fuerzas centrífugas y liberadoras, que garanticen una pluralidad de lenguajes. Se impone la adscripción a un tipo de pensamiento que proceda por aforismos, centelleos puntuales y discontinuos, en el que una multitud de posibilidades puedan realizarse, con todas sus posibles combinaciones, en cada momento. Este tipo de pensamiento 
será la condición misma para que el arquitecto se sienta autorizado a intervenir en unos tiempos sin recursos.

Se admitirá entonces que el ya consabido universo del arte conceptual, que se convertirá en obligada referencia para esta nueva forma de enfocar la ciudad, tendrá como premisa una fundamental renuncia a la objetualización, proponiendo su sustitución por elementos de tipo pasajero que asuman sus funciones urbanas por un tiempo limitado. Estos objetos tradicionales, en su dimensión visual, podrían sustituirse por

[...] fragmentos de iconicidad de significación denotativa, basada en una heterogeneidad de contenidos, simplificándose las cadenas habituales de connotaciones simbólicas a favor de los aspectos literales de la existencia física y funcional de cada material. (Marchán Fiz 1988: 214)

Este carácter de efímero y de utilización de elementos de reciclaje puede producir encuentros inesperados, yuxtaposiciones inquietantes de experiencias espaciales "post-arquitectónicas" junto con aspectos tradicionales del espacio urbano consolidado.

Se produce así un espacio urbano resultante real y virtualizado, conectado a la ciudad visible y que nos remite en clave contemporánea a las múltiples posibilidades que la misma ciudad nos ofrece, sin referirse a operaciones clásicas de duración y solidificación, propias de la época con recursos. "Es esta precariedad en todas sus formas la que produce el sentido, una suerte de resistencia cultural" (Buci-Glucksmann 2006: 27). Unas actuaciones efímeras desprovistas de melancolía que trabajan sobre lo precario y lo frágil en los estratos más propios del tiempo que del espacio, desestabilizando así lo terrestre y duradero como lugar de sentido, en provecho de un nomadismo interior y exterior, un lugar no duradero. El encanto de la captación del instante como posibilidad de diseño. Habrá pues que aprovechar esta época sin recursos como desencadenante de innovaciones continuadas a través de lo efímero, entendiendo éste como presente intensificado por un manierismo del tiempo, estrategia esencial para captar la llegada del acontecimiento. Lo efímero conquista el momento favorable, como aquello que capta tiempo en los flujos imperceptibles y entre los intervalos de las cosas, de los seres y de la ciudad, estrategia existencial y espacial atenta a lo imprevisible. El acontecimiento se convierte en texto. Se ha producido, en la época sin recursos, el paso definitivo del objeto al texto, entendido éste

[...] como espacio anti-estético en el que una variedad de escrituras, ninguna original, se mezclan y contraponen, como espacio de dimensiones múltiples que potencia el libre juego de significantes, y 
que desde luego destruye la vieja unidad indisoluble significante / significado. (Guasch 2000: 382)

La ciudad, y en concreto la ciudad histórica, tendrá que asumir el legado de la era de los recursos a través de lo efímero, pasando a adquirir una extraña apariencia, sorpresiva e inquietante, instantánea e irreal. Se producirá inevitablemente un choque semántico, que aniquilará necesariamente la ciudad artística como objeto familiar, proponiendo episodios de seducción producidos por actuaciones pasajeras que aseguren las intervenciones eficientes en el seno de una nueva era, una época definitivamente sin recursos.

Un ejemplo sencillo lo tenemos en esta propuesta presentada a un concurso convocado por la Junta de Andalucía, destinado a adquirir ideas para desarrollar distintas intervenciones efímeras en espacios públicos de la ciudad de Málaga (figuras 1 y 2).
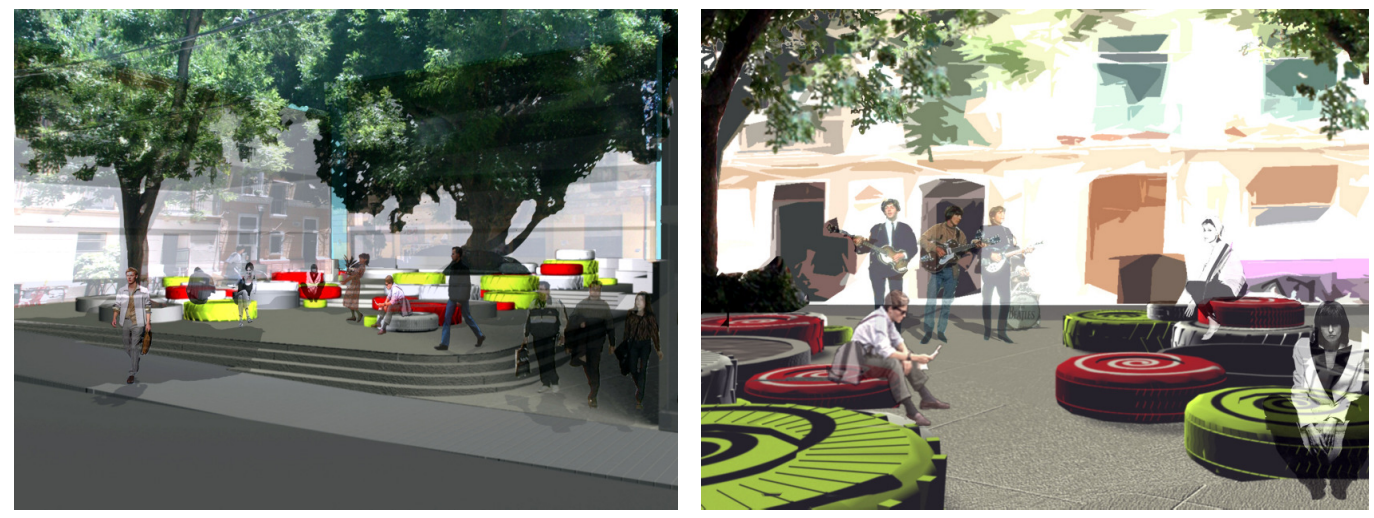

Figuras 1 y 2. Concurso AVIVA 2007. Solución a base de neumáticos para una plaza del centro histórico de Málaga. Autor: Javier Boned Purkiss.

La solución pretendía alterar la fisonomía cotidiana de una pequeña plaza del centro histórico, introduciendo objetos estandarizados de claro carácter provisional, que por su forma y ubicación podrían dotar a la plaza de funciones de las que carecía habitualmente. Así, neumáticos pequeños apilados se convertirían en pequeñas mesas; otros más grandes podrían favorecer la aparición de pequeños graderíos donde poder contemplar diversos espectáculos, otros podrían ser utilizados como jardineras provisionales. En definitiva, una solución sencilla y nada costosa que podría mejorar ostensiblemente el funcionamiento de un espacio urbano tan agradable como poco aprovechado.

En otro ejemplo referido al mismo consurso, será la creación de un espacio virtual plástico y efímero a base de papeles colgados (figuras 3 y 4 ). 

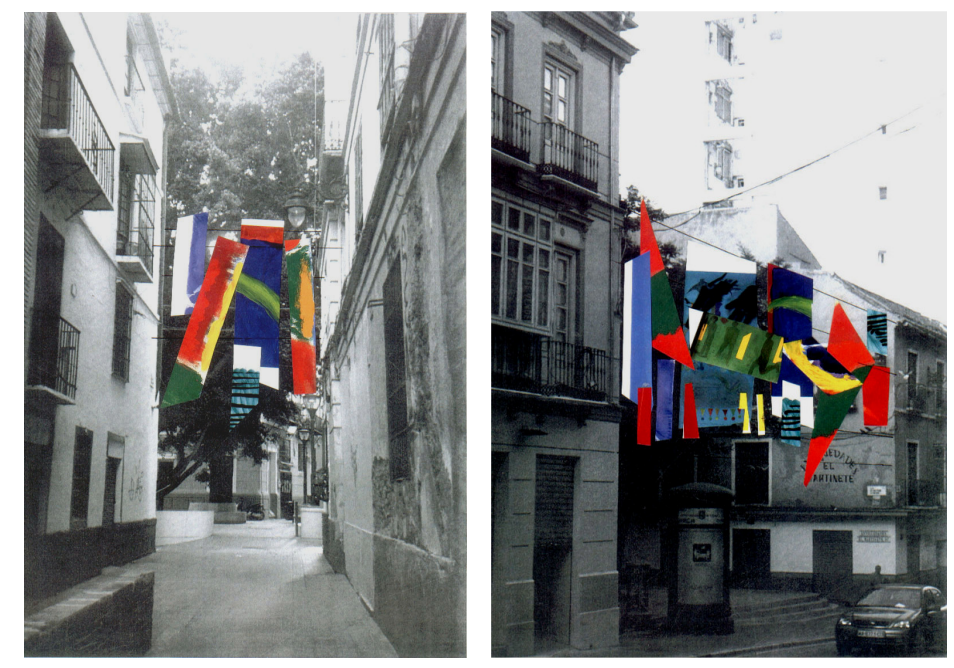

Figuras 3 y 4 . Concurso AVIVA 2007. Solución a base de papeles coloreados para una plaza del centro histórico de Málaga. Autor: Francisco Peñalosa Izuzquiza.

Asistimos a una sobrecarga de estímulos, lo que hoy día debe ser considerado como inevitable factor de atracción de la experiencia urbana, produciéndose una constante y ambigua relación entre tradición y deseo.

\section{La ciudad escuchada}

La audición parece estar esencialmente ligada a la evaluación de la situación espacio-temporal (a la que el hombre añade la vista, y el animal el olfato). La escucha, constituida a partir de la audición es, para el antropólogo, el sentido propio del espacio y del tiempo, ya que capta los grados de alejamiento y los retornos regulares de la estimulación sonora. Para el hombre también es sonora la apropiación del espacio: el espacio doméstico, el de la casa, es el espacio de los ruidos familiares, reconocibles, y su conjunto forma una especie de sinfonía doméstica. La escucha se yergue, sobre este fondo auditivo, en el ejercicio de una función de inteligencia, es decir, de selección. Cuando el fondo auditivo invade por completo el espacio sonoro (cuando el ruido ambiental es demasiado fuerte), la selección, la inteligencia del espacio, ya no es posible, y la escucha resulta perjudicada. Hoy día existe una contaminación sonora que atenta contra la misma inteligencia del ser vivo, inteligencia contra la capacidad de comunicarse adecuadamente. La polución impide escuchar. La importancia de la escucha es recalcada en estas palabras de Roland Barthes:

Como mejor captamos la función de la escucha es a través de la noción de territorio, el espacio de la seguridad, y como tal, necesitado de defensa. La escucha es la atención previa que permite captar todo lo que puede aparecer para trastornar el sistema 
territorial; es un modo de defensa contra la sorpresa. Hacia lo que está atenta es la amenaza, o por el contrario la necesidad. El material de la escucha es el índice, porque revela un peligro o porque promete la satisfacción de una necesidad. Doble función defensiva y predadora en la escucha civilizada. Es necesario -y en eso reside la misión de esta primera escucha- que lo que era confuso e indiferente se vuelva distinto y pertinente, y que toda la naturaleza tome la forma particular de un peligro o de una presa. La escucha es la operación donde esta metamorfosis se realiza. [...] Escuchar es ponerse en disposición de decodificar lo que es oscuro, confuso, o mudo, con el fin de que aparezca ante la conciencia el revés del sentido. (Barthes 1982: 246)

Hoy en día, al escuchar se le reconoce la capacidad de barrer los espacios desconocidos. La escucha incluye en su territorio no sólo lo inconsciente, sino lo implícito, lo indirecto, lo suplementario, lo aplazado. La escucha se abre a todas las formas de la polisemia, de sobredeterminación, de super-oposición; la Ley de la escucha correcta, única, se ha roto en mil pedazos.

Al escuchar prestamos atención a las leyes físicas del sonido. Cuando escuchamos música atentamente, nos fijamos en el tiempo y en el espacio de cada nota, debemos crearnos una experiencia propia de la progresión del tiempo o de la ilusión del tiempo que transcurre en el interior de aquello que escuchamos. Porque no basta con oír, al igual que no basta con mirar para poder ver. Escuchar es oír acompañado del pensamiento. El poder del oído entonces se hace perceptible cuando el sonido es diseñado intencionadamente como acompañamiento de un fondo, tal y como sucede en el cine, donde las bandas sonoras por sí mismas son capaces de hacernos entender, incluso con anterioridad a que se produzcan, cierto tipo de escenas.

Nos hemos vuelto cada vez más insensibles a la información que recibimos a través del oído, no valorando la variedad ni la calidad de sonidos que diariamente percibimos, y que condicionan sin duda nuestra existencia. Se ha hablado mucho del problema de la contaminación acústica de nuestras ciudades, la expresión audible de su actividad cultural y económica, y por tanto de su vitalidad, esa resonancia constante que a menudo se transforma para la percepción en un ruido metálico que nos irrita y nos desequilibra. A este respecto se han estudiado multitud de ciudades y se han elaborado sus correspondientes mapas acústicos que nos han ayudado a localizar y a cuantificar los aspectos de este fenómeno propio de nuestra época.

Pero el asunto del sonido urbano no debería estar únicamente referido a temas de contaminación. Ya en los años sesenta, el compositor canadiense Murray Schafer expresó el problema con total claridad y constató una pérdida progresiva de la identidad acústica en los asentamientos humanos, dado que la barrera de ruido indiferenciado que reina en muchos lugares conduce a la desaparición 
de las formas acústicas, de la riqueza estética y de la superposición espacial de sonidos de distinta profundidad.

El sonido contribuye al proceso mediante el cual los ambientes resultan lugares con una atmósfera particular, que crean sentimientos y emociones. Pero ¿cómo funciona nuestra percepción sonora? La impresión acústica está sostenida por el flujo temporal y el cambio. Mientras los elementos visuales definen el espacio de forma estable, en la dimensión acústica es fundamental el flujo y el cambio, siendo la presencia de sonidos estables o permanentes excepción a la regla. Los sonidos "van y vienen" en un estado en continuo flujo. La experiencia acústica, tal como muestran algunas investigaciones sobre percepción sonora, está basada en el aislamiento e identificación de patterns significativos, de secuencias, de sonidos extraídos del ambiente acústico que nos rodea. (Carles y Palmese 2005: 17)

Al igual que la percepción visual va dejando huellas en la retina de nuestra propia historia, identificando los lugares, los espacios y la arquitectura que han ido jalonando las distintas etapas de nuestra vida, sucede lo mismo con los recuerdos acústicos. En efecto, antes de que sobreviniera la industrialización total y se generalizara el uso del automóvil, la ciudad se hallaba estratificada acústicamente en un primer plano (nuestras conversaciones, por ejemplo), un segundo plano (quizás el pájaro del jardín) y un fondo (posiblemente la campana de la iglesia), que podían diferenciarse. Antes de la industrialización total, cada ciudad, cada barrio, podía ser reconocible por su sonido.

Con la globalización y nuestra sociedad post-industrial, la ciudad tiende a sonar igual en todas partes. Las calles y plazas de la ciudad hacen cada vez más difícil que uno se pueda orientar con ayuda de informaciones sonoras y se pueda identificar con un lugar. Los famosos no lugares de Marc Augé resultan mucho más claramente evidentes en su componente sonora. En ellos sería imposible percibir con el oído el espacio construido, el tiempo y la cultura local. El proyecto World Soundscape Project iniciado por el citado Murray Schafer, así como otras iniciativas, han abogado a nivel mundial desde los años setenta del siglo pasado por la creación de un entorno sonoro favorable. Dado el predominio de lo visual en nuestra época, su tarea no es fácil. En las tres décadas transcurridas desde que comenzaron estos proyectos, se han llevado a cabo extensos estudios de las atmósferas sonoras de las ciudades. Multitud de artistas (Neuhaus, Fontana, Kubisch, Eller...), han señalado con instalaciones sonoras e intervenciones musicales los problemas existentes y presentado propuestas para la remodelación acústica de la ciudad. En concreto, Andrés Bosshard ha llegado a plantear en ciudades como Florencia o Zurich la posibilidad de jardines acústicos, 
que interactúan con los ciudadanos y se transforman según las estaciones del año, evolucionando lentamente.

Así, el citado Murray Schafer insistió en la distinción entre campo sonoro y paisaje sonoro.

Con esta conceptualización, podemos decir que el primero, el campo sonoro, se refiere al espacio acústico generado a partir de una determinada fuente emisora que irradia y extiende su sonoridad a un área o territorio bien definidos. El centro de este campo sonoro es un determinado agente emisor, humano o material que, a medida que el sonido que produce se propaga y mezcla con otros, tiende a ver opacado e indeterminado su origen. Por eso, la expresión acústica que constituye el campo sonoro es siempre una expresión híbrida y, en cierto modo, desterritorializada. No obstante, dentro de determinados límites físicos y geográficos, al margen del espacio de la ciudad, la situación más común es la de la presencia simultánea de varios campos sonoros particulares que se sobreponen y articulan entre sí. De tal sobreposición resulta lo que se considera un paisaje sonoro, o sea, un ambiente sonoro multifacético que envuelve a los diferentes sujetos receptores. El paisaje sonoro es, de esta manera, fundamentalmente antropocéntrico ya que, al contrario de lo que sucede con el campo sonoro, no es un agente emisor indiferenciado humano o material-, sino el sujeto humano concreto quien, en su calidad de receptor, constituye su centro. Dicho de otra manera, mientras los campos sonoros hacen destacar la acción de producción/emisión de sonoridades, los paisajes sonoros se refieren al acto de su apropiación/recepción y parecen, así, capaces de reterritorializar y volver específica la acústica indiferenciada del campo sonoro. (Fortuna 2009: 39)

Porque en la ciudad lo cierto es que los ruidos y los sonidos se despegan de los personajes, de los lugares y de los nombres a los que están en principio vinculados, para formar motivos autónomos que no cesan de transformarse en el tiempo, disminuyendo o aumentando, añadiendo o sustrayendo, variando su velocidad y su lentitud. Al igual que la música en la Recherche de Proust, el sonido en la ciudad se nos presenta como bloques de duración siempre cambiantes, de velocidad variable y alteración libre, sobre una diagonal que constituye la única unidad de la obra, la transversal de todas las partes. A veces esta diagonal se plasma en configuraciones determinadas, como las producidas por ejemplo por la iluminación navideña, y al ser percibidas en movimiento ilustran inconscientemente una musicalidad (figura 5). 


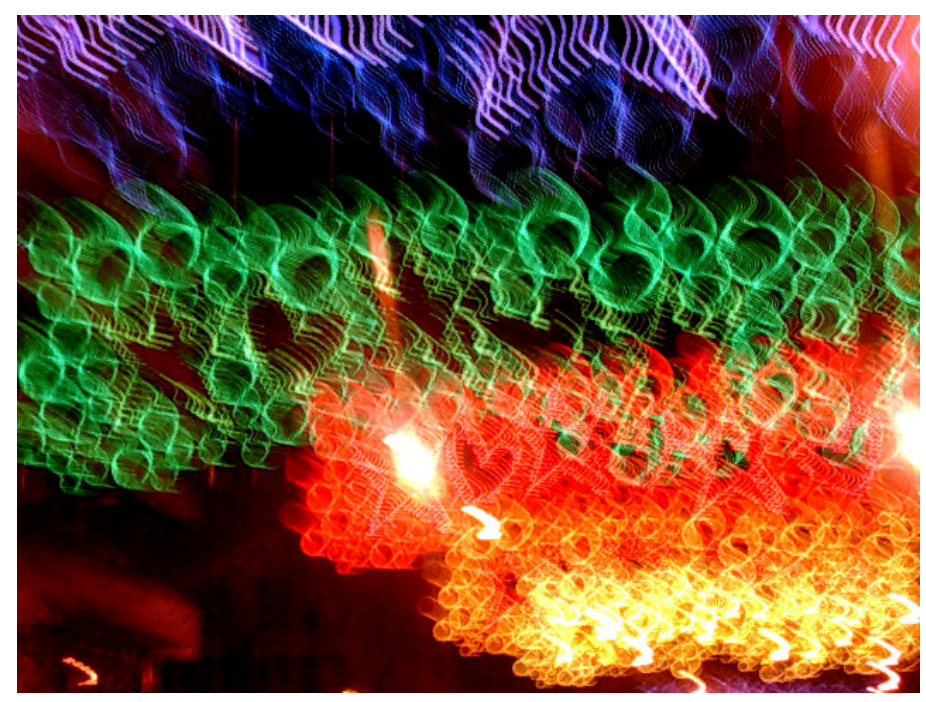

Figura 5. La ciudad como ser musical. Madrid: Ritmos y colores de iluminación navideña. Autor: Javier Boned Purkiss.

Esta diagonal perceptiva no residirá ni en las vistas verticales del paisaje, que son como planos armónicos, ni en la línea melódica del recorrido, sino en ese ir de un lado a otro, que permite fundir en un bloque de transformación o de duración la sucesión de los puntos vistos y el movimiento del punto de vista. Según Proust, la memoria incluso involuntaria ocupa una zona muy restringida, que el arte desborda por todas partes, y que sólo tiene un papel conductor. Porque el problema del arte, el problema correlativo a la creación, es el de la percepción y no el de la memoria: la música es pura presencia, y reclama una ampliación de la percepción hasta los límites del universo. "Una percepción ampliada, tal es la finalidad del arte (o de la filosofía, según Bergson)" (Deleuze 1986: 112). Ahora bien, tal meta no puede ser alcanzada más que si la percepción rompe con la identidad donde nuestra memoria la fija.

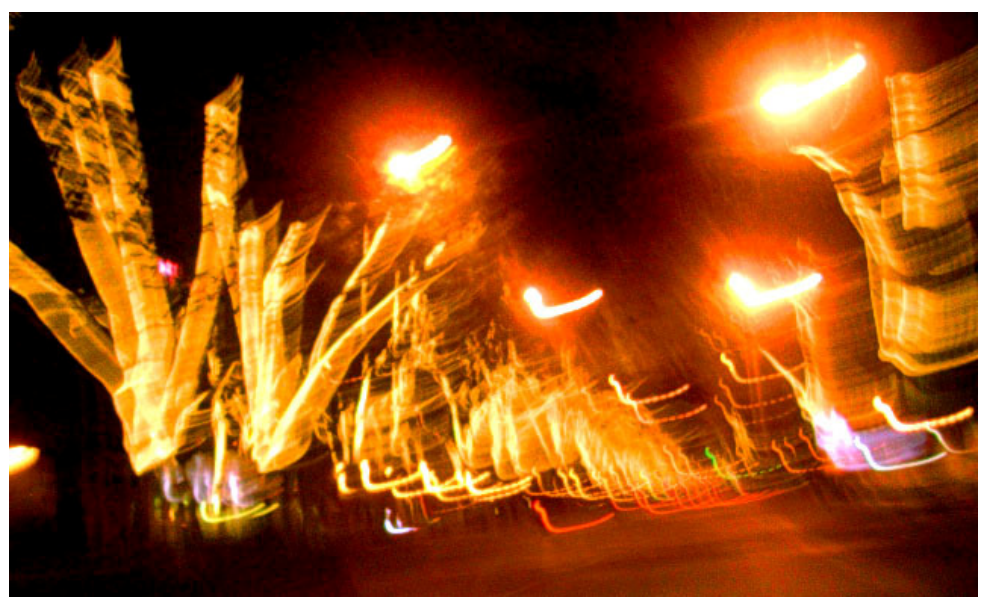

Figura 6. La ciudad como ser musical. Madrid: Ritmos y colores de iluminación navideña. Autor: Javier Boned Purkiss. 
La música siempre ha tenido ese objeto: individuaciones sin identidad, que constituyen los seres musicales. La ciudad, pues, como ser musical (figura 6), implicaría expandir o ampliar la percepción que de ella tenemos, volver sensibles, sonoras (o visibles) fuerzas ordinariamente imperceptibles. Sin duda, tales fuerzas no son necesariamente el tiempo, pero se entrecruzan y se unen a las del tiempo, que de ordinario no es visible. Percibimos con facilidad y a veces dolorosamente lo que está en el tiempo, percibimos también su forma, sus unidades y relaciones, pero no el tiempo como fuerza, el tiempo mismo. El reto pasaría por hacer del sonido el intermediario que vuelva el tiempo sensible, los números del tiempo perceptibles, organizar el material, la ciudad, para captar las fuerzas del tiempo y volverlo sonoro.

[...] Volver sonora la fuerza muda del tiempo. El músico captura y vuelve sensibles las fuerzas del tiempo desarrollando las funciones de temporalización que se ejercen en el material sonoro. Las fuerzas del tiempo y las funciones de temporalización se unen para constituir los aspectos del tiempo implicado. Como en la literatura de Proust, estos aspectos en la ciudad son múltiples, y no se reducen simplemente a "perdido-recobrado". También en la ciudad hay "un tiempo rebuscado" (le temps re-cherché), la constitución de bloques de duraciones, su recorrido en diagonal: no se trata de acordes (armónicos), sino de verdaderos cuerpo a cuerpo, a menudo rítmicos, abrazos sonoros y espaciales en que los uno de los luchadores prevalece sobre el otro, por turnos. (Deleuze 1986: 98)

La verdad es que los arquitectos y diseñadores de la ciudad podrían aportar en este campo multitud de ideas que no fueran únicamente encaminadas a la reducción de ruido (único aspecto sonoro que ha sido hasta ahora objeto de atención), sino a la integración e incluso producción de este ruido de forma cualificada, incidiendo en el mismo desde el punto de vista de su reverberación, su repetición o su textura, contrastándolo con otras emisiones sonoras que se podrían tener en cuenta en el planeamiento urbano desde un principio. Está por hacer, en este sentido, la cultura acústica de lo urbano, la cultura del sonido de la ciudad, por no decir la cultura acústica en general. A la asimilación del collage visual, signo inequívoco de nuestra civilización, deberíamos añadir la asimilación y el estudio de lo que significa el collage sonoro.

Escuchar implica pensar, y escuchar las ciudades significaría una buena disposición para entenderlas en toda su complejidad. Las ciudades hablan de lo que son a través de su imagen y de sus arquitecturas, pero también, y muy intensamente, a través de sus sonidos. Y si tan elocuentes son los códigos visuales que se instauran diariamente en nuestra percepción proporcionándonos cantidades 
ingentes de información, así lo son también los códigos sonoros, que nuestra escasamente desarrollada cultura auditiva nos impide descodificar e interpretar con la misma intensidad. La comprensión y la vivencia adecuada de nuestros espacios y nuestras ciudades estarán siempre mutiladas si no conseguimos familiarizarnos con su lenguaje sonoro. El sonido nos enseña que el pensamiento lógico y las emociones intuitivas están permanentemente unidos. El sonido, en definitiva, nos enseña que todo está relacionado.

\section{Bibliografía}

BARTHES, Roland (1982): Lo obvio y lo obtuso. Barcelona: Paidós.

BUCI-GLUCKSMANN, Christine (2006): La estética de lo efímero. Madrid: Arena Libros.

CARLES, José Luis; y PALMESE, Cristina (2005): "Paisaje sensorial" [en línea]. Revista Scherzo, núm. 203, pp. 1-25. En: www.revistasculturales.com/artículos/60/scherzo/258/4/acustica-yarquitectura-el-marco-acustico-y-su-evolucion.html.

DELEUZE, Gilles (1986): "Boulez, Proust et le temps: occuper sans compter", en Claude Samuel (ed.), Éclats/Boulez, pp. 98-100. París: Centre Pompidou.

FORTUNA, Carlos (2009): "La ciudad de los sonidos: Una heurística de la sensibilidad en los paisajes urbanos contemporáneos" [en línea]. Cuadernos de antropología social, núm. 30 pp. 39-58. En: http://www.scielo.org.ar/scielo.php?script=sci arttext\&pid=S1850275X2009000200003\&lng=es\&nrm=iso ISSN 1850-275X.

GUASCH, Anna María (2000): El arte último del siglo XX (Del posminimalismo a lo multicultural). Madrid: Alianza.

MARCHÁN FIZ, Simón (1988): Del arte objetual al arte de concepto (Epílogo sobre la sensibilidad postmoderna). Madrid: Akal, col. Arte y Estética. 